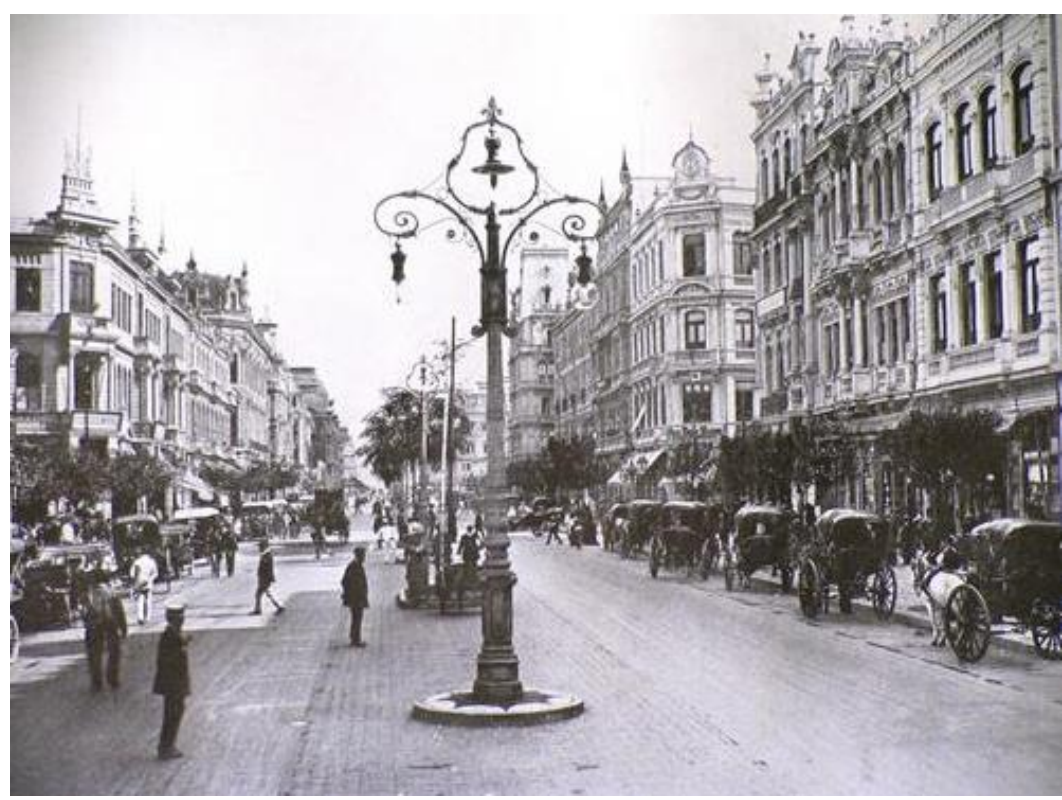

\title{
Personagens nas ruas do Rio de Janeiro do século XIX: uma leitura de $A$ moreninha (1844) e $O$ moço loiro (1845), de Joaquim Manuel de Macedo (1820-1882)
}

Characters in the streets of Rio de Janeiro of the nineteenth century: a reading of $A$ moreninha (1844) and $O$ moço loiro (1845), by Joaquim Manuel de Macedo (1820-

Joelma Santana Siqueira*

\section{Resumo:}

O presente artigo analisa a circulação dos personagens pelas ruas do Rio de Janeiro do século XIX nos dois primeiros romances do escritor Joaquim Manuel de Macedo - A moreninha (1844) e $O$ moço loiro (1845). Observa-se que na ficção inaugural do escritor circulavam pelas ruas da cidade os escravos, os homens e os jovens galanteadores. As moças se punham com frequência à janela, pois a rua era um lugar para serem vistas apenas de relance, sempre acompanhadas de familiares ou pessoas amigas. A análise permitiu-nos estabelecer relações com os temas da escravidão, da condição da mulher e da política-jurídica do Império.

Palavras-chave: Rua; Espaço ficcional; Joaquim Manuel de Macedo.

\section{Abstract:}

This article analyzes the movement of the characters on the streets of Rio de Janeiro in the first two novels of the writer Joaquim Manuel de Macedo - A moreninha (1844) and $O$ moço loiro (1845). It is observed that in the writer's inaugural fiction, slaves, men and young beaus circulated in the city streets. The girls often stood at the windows, because the street was a place where they were seen only with a glimpse, always accompanied by relatives or friends. The analysis allowed us to establish relations with the issues of slavery, the status of women, and the political Empire.

Keywords: Street; fictional space; Joaquim Manuel de Macedo.

\footnotetext{
* Professora permanente do Programa de Pós-graduação em Letras da Universidade Federal de Viçosa. Emails: jandraus@ufv.br/jandraus@yahoo.com Endereço: Universidade Federal de Viçosa. Departamento de Letras, Sala 10. CEP 36570-000 Viçosa-MG.
} 
É conhecida a observação do quanto o nosso romance deu vistas às descrições do espaço brasileiro, tanto no que diz respeito ao campo, quanto à cidade. A esse respeito, dois textos são exemplares: "Notícia da atual literatura brasileira", também conhecido por "Instinto de nacionalidade", publicado por Machado de Assis em 1873, pois aponta na literatura brasileira do período em questão um excesso de "cor local", um descritivismo da natureza, costumes etc., nem sempre justificável; e o capítulo "Um instrumento de descoberta e interpretação", pois aborda os primórdios do romance brasileiro, considerando que o nosso romance tinha sede de espaço, presente em um dos estudos mais famosos do crítico e historiador Antonio Candido, Formação da literatura brasileira, publicado pela primeira vez em 1959.

A descrição do espaço físico esteve no centro das atenções dos primeiros romancistas como um dos aspectos que garantiria verossimilhança à ficção. Porém, vale lembrar que o verossímil não se encontra na mera cópia do real, mas no reconhecimento e na validade do mundo fictício criado pelo autor, correspondentes às convenções do gênero ao qual se filia a obra. Na literatura, os escritores muitas vezes produziram visões do espaço mais idealizadas do que tensionadas com a realidade.

O escritor Joaquim Manuel de Macedo é mais conhecido do grande público como o autor do primeiro romance brasileiro. Foi um escritor que se dedicou com afinco à produção literária, tendo sido considerado em vida uma das maiores figuras da literatura, vindo a perder prestígio apenas quando do sucesso de José de Alencar. Produziu poesia, romance, teatro, crônica e textos oficias escritos sob encomenda. Entre as crônicas de sua autoria, destacam-se os volumes Um passeio pela cidade do Rio de Janeiro (1862-63) e Memória da Rua do Ouvidor (1878).

Em seu primeiro romance, A moreninha (1944), a narrativa centra-se no cotidiano de jovens do interior, filhos da elite, que vieram para o Rio de Janeiro estudar. Daí morarem em repúblicas e serem tão atraídos pelas festas dos parentes de seus colegas de faculdade. Poucas cenas se desenrolam na rua, mas, dentre estas, uma nos chama a atenção logo no início da narrativa. Trata-se do momento em que o estudante Augusto empresta seu escravo Rafael ao amigo Fabrício. Como o escravo demora a retornar, Augusto reflete sozinho:

Vejam isto!... já tocou a recolher e Rafael está ainda na rua! Se cai nas unhas de algum buleguim, não é, decerto o Sr. Fabrício que há de pagar as despesas da Casa de Correção... Pobre do Rafael! Que cavaco não dará quando lhe raparem os cabelos! (MACEDO, 1987, p.16) 
A passagem acusa a existência de regras para o uso do espaço público da rua à noite pelo escravo, sujeito a represálias por parte do poder constituído. Esta situação, de acordo com Sidney Chalhoub, não dizia respeito apenas ao escravo, mas também ao africano liberto, posto que

[...] havia restrições importantes a seus movimentos e atividades, estabelecidas em posturas municipais país afora. Em deslocamentos dentro do município de Salvador, por exemplo, havia postura, de 1859, determinando multa a escravos que estivessem à noite nas ruas sem bilhete assinado pelo proprietário, no qual se declarasse nome do portador, destino da caminhada e local de residência; do mesmo modo, africanos libertos seriam penalizados com multa de 3 mil-réis, ou oito dias de prisão, se fossem encontrados nas ruas à noite sem levar 'bilhetes de qualquer Cidadão Brazileiro'. Dito doutra forma, um liberto africano nem podia se locomover pela cidade em certas horas sem a proteção de um homem livre, alguém disposto a lhe abonar a conduta por bilhete (CHALHOUB, 2010, p.41).

A citação acima explica-nos a preocupação de Augusto sobre a permanência do escravo à noite nas ruas da cidade. A respeito desse tema, Raquel Rolnik, em um artigo intitulado "Territórios negros nas cidades brasileiras (etnicidade e cidade em São Paulo e Rio de Janeiro) ", observou que "o tema empírico do negro nas cidades até agora foi pouco explorado nos textos brasileiros da sociologia do negro ou da sociologia urbana". Para a autora, a rua era território dos negros, pois

[...] a contiguidade dos sobrados nas zonas centrais das cidades contribuía para que fosse intensa a circulação de escravos domésticos: buscando água nos chafarizes, indo ou voltando com a roupa ou os despejos para jogar nos rios, carregando cestas perto dos mercados, transportando objetos de um ponto para outro da cidade ${ }^{1}$.

O romance A moreninha, que tem como tema, sobretudo, o modo como o namoro era visto pelos jovens estudantes e pelas jovens moças casadoiras da época, faznos rir em muitas situações do amor idealizado e apresenta cenas que nos permitem observar a condição do escravo na sociedade brasileira do século XIX. Dois escravos são mais frequentemente focalizados na narrativa: o "bom Rafael" e a ama Paula. Esta última era "muito estimada de todos" da família, principalmente por ser estimada por Carolina. Rafael pertencente a Augusto, e Paula, a Carolina. Augusto e Carolina são os protagonistas do romance. Rafael, mesmo sendo o "querido moleque" de Augusto, o seu faz tudo, é castigado indiscriminadamente por seu dono quando este sofre dores de amor

\footnotetext{
${ }^{1}$ Ver ROLNIK, Raquel. "Territórios negros nas cidades brasileiras (etnicidade e cidade em São Paulo e Rio de Janeiro). Disponível em http://raquelrolnik.files.wordpress.com/2013/04/territc3b3rios-negros.pdf Acessado em 27 de jun. de 2013
} 
por Carolina. O narrador nos diz que "se o inocente moleque lhe apronta o chá muito cedo, apanha meia dúzia de bolos, porque quer ir vadiar pelas ruas; se no dia seguinte se demora só dez minutos, leva dois pescoções, para andar mais ligeiro" ( $M$, p. 127) ${ }^{2}$. Augusto desconta no pobre do Rafael seu mal humor do momento.

Outros escravos domésticos são descritos como "decentemente vestidos" em dias de festa, servindo os convidados. Há também a presença de escravos de ganho, a exemplo de uma preta que vende empadas e se encarrega de levar cartas de namoro da jovem Gabriela, amiga de Carolina. Tobias, escravo considerado um "maldito criolo" pelo estudante Fabrício, é, na visão deste personagem, um escravo astuto e que o extorque, cobrando em demasia pelas cartas que entrega a sua pretendente. Não há menção ao nome das ruas percorridas pelos escravos. Fabrício conta que a primeira vez que encontrou o escravo Tobias, na porta de um camarote do teatro, após perguntar-lhe se pertencia às jovens que ele observava, o escravo respondeu que sim e que "elas moram na rua de... número... ao lado esquerdo de quem vai para cima" ( $M$, p.19). Suprimir os nomes dos lugares poderia causar curiosidade no leitor.

A mentalidade dos jovens, muitas vezes, nada romântica, é percebida pelos diálogos que trocam entre si. Fabrício contou a Augusto que evitava namorar moça de sobrado como uma medida econômica, pois evitava pagar o moleque para levar os recados e podia dar "sossegadamente, e à mercê das trevas", seus "beijos entre os postigos das janelas" ( $M$, p.16). O estudante Leopoldo, por sua vez, explicou a Augusto o que pensa sobre as moças da roça e as moças da cidade:

- Tu falas em amor, Augusto? Ainda bem que somos ambos estudantes da roça e posso dizer-te agora o que entendo, sem medo de ofender suscetibilidade de cortesão algum. Pois ainda não observaste que $o$ verdadeiro amor não se dá muito com os ares da cidade? ... que por natureza e hábito, as nossas roceiras são mais constantes que as cidadoas? Olha, aqui encontramos nas moças mais espírito, mais jovialidade, graça e prendas, porém, nelas não acharemos nem mais beleza, nem tanta constância. Estudemos as duas vidas. A moça da Corte escreve e vive comovida sempre por sensações novas e brilhantes, por objetos que se multiplicam e se renovam a todo momento, por prazeres e distrações que se precipitam; ainda contra a vontade, tudo a obriga a ser volúvel: se chega à janela um instante só, que variedade de sensações! Seus olhos têm de saltar da carruagem para o cavaleiro, da senhora que passa para o menino que brinca, do séquito do casamento para o acompanhamento de enterro! Sua alma tem que sentir ao mesmo tempo o grito de dor e a risada de prazer, os lamentos, os brados de alegria e o ruído do povo; depois tem o baile com sua atmosfera de lisonjas e mentiras, onde ela se acostuma a fingir o que não sente, a ouvir frases de amor a todas as horas, a mudar de galanteador em cada contradança; depois

\footnotetext{
2 Todas as citações da obra $A$ moreninha dentro dos parágrafos foram referidas por meio da abreviação "M" e página.
} 
tem o teatro onde cem óculos fitos em seu rosto parecem estar dizendo: és bela! E assim enchendo-a de orgulho e muitas vezes de vaidade; finalmente, ela se faz por força e por costume tão inconstante como a sociedade em que vive, tão mutável como a moda dos vestidos. Quereis agora ver o que se passa com uma moça da roça? ... (MACEDO, 1987, p.130-1).

A passagem reporta-nos tanto à visão do homem jovem sobre a mulher solteira quanto a questões relacionadas à condição dessa mulher na sociedade brasileira do século XIX. A esse respeito, Ubiratan Machado (2001, p.256) destacou que abrir as janelas da casa foi uma das mais importantes vitórias da mulher para atenuar sua condição servil, na década de 1840, pois tornando-se janeleiras, "as jovens namoravam quem queriam, tramavam fugas com os amados, ganhavam forças e astúcias para resistir às imposições paternas”.

O tema da condição da mulher na sociedade aparece no romance de modo reivindicatório pela personagem Carolina, a moreninha, que é defensora dos direitos das mulheres e leitora de Mary de Wollstocraft, autora de Direito das mulheres e injustiça dos homens, obra traduzida em 1832 por Nísia Floresta, considerada precursora dos ideais feministas no Brasil. Trata-se de um tema recorrente na obra de Macedo.

O segundo romance do escritor, publicado em 1845, narra o roubo de um bem de família, supostamente, por um jovem neto da matriarca. A essa história vem juntar-se os episódios de um moço loiro misterioso que coteja uma jovem dessa mesma família, prima do suposto ladrão. Os encontros fortuitos entre os dois jovens ocorrem em ocasião de festa e passeio, nos famosos saraus, quando as casas da elite abriam as portas para a apreciação pública, fazendo com que, como escreveu Maria Ângela D’Incao (2004, p.228), os salões funcionassem como "espaços intermediários entre o lar e a rua”, tanto para as mulheres quanto para os homens. Para elas porque, de acordo com o narrador desse segundo romance, seu grande campo de batalha "é pois a noite de sarau", onde podem se ostentar por inteiro "desde a flor do cabelo até o bico do sapato" $(M L$, p.70) ${ }^{3}$, e não pela metade, como no camarote dos teatros, ou de relance, como no passeio público; e para os homens porque ali também se discutia negócios e política.

Há nesse segundo romance muito mais referências aos espaços públicos do Rio de Janeiro. O primeiro capítulo começa em um fim de tarde do dia 06 de agosto de 1844, com o tempo "chão e bonançoso" e o Pão de Açúcar com sua cabeça “desnublada". A primeira cena se passa na Rua Direita, que, como nos diz o narrador,

\footnotetext{
${ }^{3}$ Todas as citações da obra $O$ moço loiro dentro dos parágrafos foram referidas por meio da abreviação "ML" e página.
} 
"efetivamente representa a antítese do próprio nome" ( $M L$, p.11). Esta rua, informou Macedo em suas Memórias da Rua do Ouvidor, foi a principal e mais rica do comércio, abrigando as modistas francesas até que se mudassem para a obscura Rua do Ouvidor, por volta de 1821-22. No momento em que a narrativa começa, a Rua do Ouvidor já tem a sua importância e o narrador nos conta que Brás Mimoso, personagem solteirão e galanteador, "frequenta muito a Rua do Ouvidor, sabe de modas e de vestidos como $\mathbf{M}^{\mathrm{me}}$ Gudin, de flores como $\mathrm{M}^{\mathrm{me}}$ Finot, de cosméticos e pomadas como $\mathbf{M}^{\mathrm{me}}$ Desmarais" (ML, p.25).

O hábito das moças de portarem-se à janela recebe uma longa reflexão do narrador de $O$ moço loiro. Na passagem abaixo, ele ironiza a moça que fica de janela:

Uma moça loureira, que está de janela, e que é do número dessas que sabem estar de janela, põe em ação a ciência mais difícil do mundo, e que é ao mesmo tempo tão positiva como a matemática, e tão cheia de - coisas nenhumas -, como a diplomacia: ela tem a vista tão segura, que pelo menear da bengalinha conhece o jovem, que vem do princípio da rua... (MACEDO, 1981, p.54).

O narrador refere-se aos significados atribuídos às reações das janeleiras ao verem um jovem mancebo atravessar a rua. Porém, a condição da mulher na sociedade é um assunto discutido principalmente pela personagem Raquel, jovem amiga de Honorina para quem o pai fez questão de revelar as artimanhas dos homens frequentadores de saraus, falsos conquistadores do coração feminino. Raquel ensina a Honorina que o fim da mulher é o casamento e esse está garantido para as belas e principalmente ricas como elas. Com ironia, comunica à amiga que

a senhora de grande dote é o amor... o cálculo do futuro; a bela jovem de fracos teres é o amor... o passatempo do presente: vivemos em um século de frias ideias, em uma época de algarismos; tudo é positivo... o comércio tem invadido tudo: negocia-se também com o sentimento (MACEDO, 1981. p.33).

O segundo romance de Macedo pode ser considerado um romance de mistério. Um crime foi cometido, o roubo de uma relíquia de família, e será desvendando no final. Mas a esse mistério vem juntar-se outro: o de um moço loiro, misterioso, a cortejar a jovem Honorina, filha de Hugo de Mendonça, a quem seria destinada a relíquia roubada.

Observa-se a presença dos escravos domésticos, com destaque para Lúcia, ama de Lauro, o primo de Honorina acusado de roubo pela família. Há a menção à importação de escravos por parte do falecido pai de Hugo de Mendonça, que entrou "em 
empresas arriscadas... tinha parte muito notável no contrabando de africanos" ( $M L$, p.153). Nota-se que o contrabando de escravos, na época em que se passa a narrativa, era proibido por causa do tratado assinado entre Brasil e Inglaterra em 1826 e uma lei promulgada em 7 de novembro de 1831. Como se pode observar, na ficção de Macedo, era muito mais uma "lei para inglês vê", pois o tráfego permanecia. $\mathrm{Na}$ vida real, não era diferente, pois, como escreveu o historiador Boris Fausto (2006, p.194), “os júris locais, controlados pelos grandes proprietários, absolviam os poucos acusados que iam a julgamento".

Há um personagem jovem, filho de uma família endividada, mas preocupada em manter as aparências, que merece destaque na narrativa. Trata-se de Manduca, um jovem bastante ingênuo, porém, ao pensar em ocupar-se da política, de acordo com o narrador, mostrou em toda sua longa vida ter algum discernimento. Manduca reflete que “a política é para a maior parte um jogo que nunca se perde: quando não se ganha hoje, tem-se um bocadinho de paciência, e amanhã lucra-se por dois dias”. O narrador logo em seguida acrescenta: “ora confessemos que Manduca tinha razão" (ML, p.142). A respeito da política no contexto em questão, Boris Fausto (2006, p.181), observado que as diferenças entre os dois grandes partidos imperiais (o Conservador e o Liberal) são interpretadas de diferentes modos pela historiografia, considerou que devemos ter em conta que, nesse período, "e não só nele”, a política "em boa medida não se fazia para se alcançarem grandes objetivos ideológicos. Chegar ao poder significava obter prestígio e benefícios para si próprio e sua gente". Manduca percebe desse fato e por isso é elogiado pelo narrador. Há uma ironia na narrativa ao nos fazer pensar que mesmo Manduca, tão ingênuo, foi capaz de interpretar a política de seu tempo. No entanto, alguns pensamentos atribuídos a Manduca parecem muito mais apropriados ao narrador:

\begin{abstract}
Aí, apesar das teimosas e desprezíveis discussões das necessidades da província, um homem faz por habilitar-se: tratando-se de um chafariz, enxerta-se um discurso sobre política geral... discutindo-se os melhores meios de esgotamento, vem mesmo a apelo uma alongada dissertação sobre as mais intricadas questões financeiras; e enfim na discussão de uma ponte pode um orador de habilidade entrar pela pasta dos negócios estrangeiros adentro, posto que ande ela quase sempre fechada com o muito cômodo e abençoado selo das questões pendentes (MACEDO, 1981, p.142).
\end{abstract}

A passagem destaca que as discussões sobre as necessidades materiais da província, sobre as melhorias do espaço público da província, consideradas "teimosas e desprezíveis", são oportunidades para o político se promover por meio de discursos mirabolantes. As reflexões foram atribuídas ao inocente Manduca pelo narrador, mas se 
parecem muito mais com ideias do segundo, por sua vez, espécie de porta-voz do escritor que, em 1845, ano da publicação de $O$ moço loiro, tornara-se membro oficial do Instituto Histórico e, em 1849, ingressara na política, eleito Deputado à Assembleia Provincial do Rio de Janeiro e Deputado Geral por duas legislaturas, como representante do Partido Liberal ${ }^{4}$.

A família de Hugo de Mendonça, especialmente sua mãe, Ema, a matriarca, avó de Honorina e Lauro, é tradicional e carrega ideias muito retrógadas a favor da permanência do julgo da metrópole sobre o Brasil. Como diz a ama Lúcia para Honorina, “a Sra D. Ema está exatamente no ponto em que estava há cinquenta anos atrás" ( $M L$, p.65). Se pensarmos que a personagem diz isso no ano de 1844 , cinquenta ano atrás corresponde ao tempo em que o Brasil era colônia de Portugal, portanto, contexto no qual Ema viveu parte de sua vida. O narrador nos diz que "O neto Lauro, por sua vez, era considerado pela avó um liberal, pois mesmo em sua presença "atreviase a combater e a zombar" de suas "nobres crenças, a que ele ousava dar o nome de prejuízos dos séculos de escravidão, e ignorância” ( $M L$, p.52). Expulso da família, porém, o jovem se tornou dono de "uma embarcação carregada de algumas centenas de míseros africanos" que soçobrara e "ele só, lutara vinte horas dentro de um pequenino batel contra a fúria dos ventos e do mar, finalmente conseguindo chegar à praia de Itapuã...” (ML, p.188), na Bahia. O liberalismo de Lauro era, portanto, relativo. Mais uma vez Boris Fausto nos ajuda a refletir sobre esse fato na ficção, pois segundo o historiador "a defesa das liberdades e de uma representação política mais ampla dos cidadãos foram bandeiras levantadas pelo Partido Liberal, mas foi só a partir da década de 1860 que estes temas ganharam força em seu ideário, juntamente com a retomada das propostas de descentralização" (FAUSTO, 2006, p.182).

Há mais deslocamentos no espaço público nesta segunda obra, principalmente por parte dos personagens brancos. O primo expulso da casa da avó irá morar na cidade da Bahia; o personagem Felix, guarda-livros de Hugo de Mendonça, vai a São Cristóvão de ônibus; o cais da Rua Fresca dá acesso à travessia entre o Rio e Niterói, sendo utilizado pela jovem Honorina sempre acompanhada de seu pai e dividida entre a corte e o campo; alguns personagens se reúnem para passeios de batéis pelo mar entre $\mathrm{S}$. Domingos e a praia do Gravatá; Hugo de Mendonça muda-se com a filha de Niterói para o Bairro da Glória, "bairro alegre e aristocrático”, onde "a diplomacia e a riqueza

\footnotetext{
${ }^{4}$ Consultar: "Resumo biográfico". In: MACEDO, Joaquim Manuel de. A luneta mágica. São Paulo: Ática, 1995.
} 
têm, no Rio de Janeiro, assentado o trono de seus prazeres" (ML, p.156); uma sege leva Félix e o moço loiro misterioso "a galope, deixando atrás de si diversas ruas tortuosas e feias da nossa cidade velha, e depois o Largo da Ajuda, o Passeio Público, o Largo da Lapa, e o cais da Glória, entrou finalmente na rua diplomática...” ( $M L$, p.201).

O Passeio Público, construído entre 1779 e 1783, passou por várias reformas, como a de 1817, com alterações drásticas no trabalho original de Mestre Valentim, como a substituição dos pavilhões quadrangulares pelos octogonais e a retirada das estátuas de Apolo e Mercúrio. Essas informações estão presentes no terceiro romance de Macedo, Os dois amores (1848), pela voz do distinto personagem Anacleto. No primeiro volume da obra Um passeio pelo Rio de Janeiro, que não deixa de ser um registro poético sobre a história e os usos de alguns lugares do Rio de Janeiro e tem servido de consulta para vários estudiosos da história cultural do Brasil Império, encontra-se a voz de um cronista minucioso, que narra com imaginação a origem do Passeio Público, seus usos pela comunidade e as mudanças pelas quais ele passou:

Quereis, pois, fazer ideia do que era para o povo do Rio de Janeiro o Passeio Público naquela época, e ainda em outras posteriores, a despeito dos desmazelos dos governos? Perguntai qual foi a origem de Belas Noites, dada à rua que depois muito prosaicamente chamaram das Marrecas.

Aquele nome "rua das Belas Noites" queria dizer que o Passeio Público fizera o povo do Rio de Janeiro gostar pouco a lua nova e aborrecer a minguante.

Por quê? Eis ai todo o segredo desse desamor e desse aborrecimento por aquelas duas fases da lua.

Nas noites brilhantes de luar, dirigiam-se alegremente para o Passeio Público numerosas famílias, galantes ranchos de moças, e por consequência, cobiçosos ranchos de macebos; e todos, depois de passear pelas frescas ruas e pelo ameno e elegante terraço, iam, divididos, em círculos de amigos, sentarse às mesas de pedra, e debaixo dos tetos de jasmins odoríferos ouviam modinhas apaixonadas, e lundus travessos, cantados ao som da viola e da guitarra, rematando sempre esses divertimentos com excelentes ceias dadas ali mesmo (MACEDO, 2004, p.127-8).

O Passeio Público, de acordo com Macedo, era frequentado pelas famílias burguesas, que ali desfrutavam de momentos de descontração e lazer coletivo. Macedo memorialista revive o que foi o Passeio Público no passado e acusa a falta de preservação da memória do brasileiro, que altera seus espaços públicos, trocando-lhes inclusive o nome, sem se preocupar com o sentido simbólico dos mesmos para as gerações passadas, a ser transmitido às gerações futuras.

As crônicas que compõem a obra Um passeio pela cidade do Rio de Janeiro foram publicadas, inicialmente, em forma de folhetim semanal no Jornal do Commercio e, depois, reunidas em dois volumes publicados em 1862 e 1863. As passagens 
dedicadas ao Passeio Público são concluídas com a tristeza de não vê-lo inaugurado depois de mais uma vez necessitar de reformas que, às vezes, terminam, opinião de Macedo, "com a profanação da arte". A reinauguração do Passeio, como informa Diogo de Hollanda, responsável pelas notas que acompanham a edição aqui consultada, publicada pela Editora Planeja em 2004, “ocorreria apenas em 07 de setembro de 1962, $40^{\circ}$ aniversário da Independência".

Nos dois primeiros romances do escritor, os escravos são personagens que servem aos brancos e à narrativa. Exercem função importante para o desenvolvimento da trama, a exemplo de Lúcia, do romance Os dois amores, que é ama e ajudante secreta indispensável para manutenção do mistério e do sucesso final do moço loiro. Macedo apenas começou a situar seus personagens no espaço público, coisa que fará com mais intensidade em seu terceiro romance, Os dois amores (1848), que aborda a história de amor entre um jovem pobre e uma jovem rica, ambos morando um ao lado do outro, ele em uma casa muito pobre e feia, odiada pelos vizinhos, e ela em uma casa rica, querida de todos no Bairro da Lapa do Desterro. O escritor também apenas tocou em questões políticas que serão mais esmiuçadas na obra A luneta mágica (1969), narrativa na qual um personagem míope obterá uma luneta que o levará a perceber os sentidos das coisas além das aparências. E, por fim, a escravidão foi focaliza nos dois primeiros romances do escritor, mas será aprofundada na obra As vítimas algozes (1969), que no título sintetiza a condição do escravo no seio da sociedade burguesa.

Nos dias atuais, a leitura das duas obras iniciais do escritor, além de importante para os estudiosos da literatura brasileira, no sentido de nos permitir rever noções cristalizadas pela crítica a respeito do romance brasileiro no seu nascedouro, é importante também para outros estudiosos da cultura, por permitir ao leitor observar que a ficção dialoga com muitos aspectos contraditórios da sociedade brasileira do século XIX, nem sempre observados à primeira vista.

\section{Referências bibliográficas}

ASSIS, Machado. "Instinto de nacionalidade". Disponível em http://www.ufrgs.br/cdrom/assis/massis.pdf_. Acesso em 19 de maio de 2010.

CANDIDO, Antonio. 2000. Formação da literatura brasileira: momentos decisivos. vol. II 6 ed. Belos Horizontes: Itatiaia. 
CHALHOUB, Sidney. "Precariedade estrutural: o problema da liberdade no Brasil escravagista (século XIX) ”. História Social revista dos pós-graduandos da Unicamp. n. 19 (2010).

D’INCAO, Maria Ângela. 2004. "Mulher e família burguesa”. In. História das mulheres no Brasil. São Paulo: Contexto.

FAUSTO, Boris. 2006. História do Brasil. São Paulo: Edusp.

MACHADO, Ubiratan. 2001. A vida literária no Brasil durante o romantismo. Rio de Janeiro: UERJ,

MACEDO, Joaquim Manuel de. 1987. A moreninha. São Paulo: Círculo do Livro.

1995. A luneta mágica. São Paulo: Ática, 1995. s/d. Memórias da Rua do ouvidor. São Paulo: Saraiva, s/d. 1981. O moço loiro. São Paulo: Ática.

1964. Os dois amores. São Paulo: W. M. Jackson Editores. 2004. Um passeio pela cidade do Rio de Janeiro. vol I.São Paulo: Planeta.

PEREIRA, Astrojildo. 2005. “Joaquim Manuel de Macedo". In: MACEDO, Joaquim Manuel de. Um passeio pela cidade do Rio de Janeiro. Brasília: Senado Federal, Conselho Editorial.

ROLNIK, Raquel. "Territórios negros nas cidades brasileiras (etnicidade e cidade em São Paulo e Rio de Janeiro). Revista de Estudos Afro-Asiáticos. Centro de Estudos Afro-Asiáticos n. 17 (1989). Disponível em http://raquelrolnik.files.wordpress.com /2013/04/territc3b3rios-negros.pdf Último acesso em 27 de jun. de 2013. 
Para citar essa obra:

SIQUEIRA, J. S. Personagens nas ruas do Rio de Janeiro do século XIX: leitura de "A Moreninha" (1844) e "O Moço Loiro", de Joaquim de Manuel Macedo. In: RUA [online]. 2014, $\mathrm{n}^{\circ}$. 20. Volume 1 - ISSN 1413-2109. Consultada no Portal Labeurb Revista do Laboratório de Estudos Urbanos do Núcleo de Desenvolvimento da Criatividade www.labeurb.unicamp.br/rua/

Capa: s/n. s/d. Avenida Central, esquina com Rua do Ouvidor. Disponível em: https:// lh4.googleusercontent.com/4vEeTawx7HQ/TWugesfr7I/AAAAAAAAASM/pnbxfLVS 0ak/s640/blog22.png

Laboratório de Estudos Urbanos - LABEURB

Núcleo de Desenvolvimento da Criatividade - NUDECRI

Universidade Estadual de Campinas - UNICAMP

http://www.labeurb.unicamp.br/

Endereço:

LABEURB - LABORATÓRIO DE ESTUDOS URBANOS

UNICAMP/COCEN / NUDECRI

CAIXA POSTAL 6166

Campinas/SP - Brasil

CEP 13083-892

Fone/ Fax: (19) 3521-7900

Contato: http://www.labeurb.unicamp.br/contato 